\title{
Gingival angioleiomyoma mimicking as pyogenic granuloma- A report of rare case
}

\author{
Prenika Sharma ${ }^{1, *}$, Saima Tariq ${ }^{2}$ \\ ${ }^{1}$ PG Student, ${ }^{2}$ Post MDS, Dept. of Oral Medicine and Radiology, Government Dental College, Srinagar, Jammu and Kashmir, India
}

*Corresponding Author: Prenika Sharma

Email: prenikasharma19@gmail.com

\begin{abstract}
Leiomyomas are the smooth muscle tumors that most commonly occur in the uterus, skin and gastrointestinal tract. They are benign in nature and rarely seen in oral cavity and it accounts for $0.42 \%$ of all oral soft tissue tumors. Angioleiomyomas are believed to be originated from perivascular area of blood vessels. Angioleiomyomas presents a diagnostic challenge as its clinical features are non-specific that mimics other exophytic lesions and is usually misdiagnosed.

Here we are reporting a case of angioleiomyoma in a 14- year- old Kashmiri boy. It is very rare case involving mandibular gingiva. Clinically Lesion presented as reactive inflammatory hyperplasia and histopathologic examination revealed features of angioleiomyoma.
\end{abstract}

Keywords: Angioleiomyoma (ALs), Benign tumor, Pyogenic granuloma, Histopathology (HPE).

\section{Introduction}

Leiomyoma is classified on the basis of histopathology into three types on the basis of histopathology: i) solid leiomyoma, ii) vascular leiomyoma (angiomyoma, angioleiomyoma), and iii) epithelioid leiomyoma. Leiomyomas may occur anywhere in the body but most commonly arises in the muscular layer of the gut and the body of the uterus. ${ }^{1}$

The oral cavity very rarely affected and such cases account for only $0.42 \%$ of all neoplasms of the soft tissue and $0.06 \%$ of all Leiomyomas. ${ }^{3,4}$ In the head and neck region most common site is the lips $(27.46 \%)$ followed by tongue $(18.30 \%)$, cheeks and palate $(15.49 \%)$, gingiva $(8.45 \%)$ and mandible $(5.63 \%) .{ }^{5}$

Its etiology is unknown, but hypotheses suggest minor traumas, venous stasis, hormone dysfunctions, and genetic alterations as possible etiology. ${ }^{6}$ Clinically the oral leiomyoma characterized by a small $(<2 \mathrm{~cm})$ and solitary nodular mass, it is asymptomatic but there may be symptoms such as pain, teeth mobility or difficulty in chewing.

From the clinical presentation of the lesion it is very difficult to differentiate it from other mesenchymal tumors. The diagnosis is determined by histopathologic examination.

\section{Case History}

Presented case is a 13 year old Kashmiri boy. Patient complains of painless growth on the left lower pre molar region since 6 month. According to patient growth was of pea- size initially he used to rupture it with toothpick and blood oozes out and it diminishes in size. With time it has increased to present size. On clinical examination a welldemarcated, erythematous, exophytic lesion measuring $0.8 \times 0.7 \times 0.4 \mathrm{~cm}$ in size present on left mandibular region in relation to 34,35 . It was pedunculated and had smooth surface, firm, non-tender on palpation (Fig. 1). There were mild calculus deposits in that area. Radiographic examination did not reveal any changes in the alveolar bone. (Fig. 2 and 3). His medical and family history was nonsignificant. Routine blood investigations were within normal limits and serology for hepatitis B, C and HIV was negative.

Under all aseptic precautions excisional biopsy was performed. There was perfuse bleeding at the lesion site. Hemostasis achieved with help of hemostatic agents (Citric Acid - $2.5 \mathrm{mg} / 5 \mathrm{ml}$, Butyl Alcohol - $0.26 \mathrm{mg} / 5 \mathrm{ml}$ ). 3 intermittent Sutures placed with $4 / 0$ non-resorbable silk suture, sample sent for Histopathological examination.

Amoxicillin and clavulinic acid $375 \mathrm{mg}$ was given thrice a day for 3 days, while ibuprofen was prescribed as an analgesic along with chlorhexidine gluconate rinse $(0.12 \%)$. The postoperative recovery of the patient was uneventful and his sutures were removed after 7 days. The patient reported recurrence after two month of follow-up and he was referred to oral surgery department for the complete excision of the lesion. (Fig. 3 and 4)

On histopathologic examination (hematoxylin and eosin stain) section shows features consistent with vascular leiomyoma with central foci of dystrophic calcification and overlying surface ulceration covered with acute inflammatory exudates (Fig. 5, 6). 

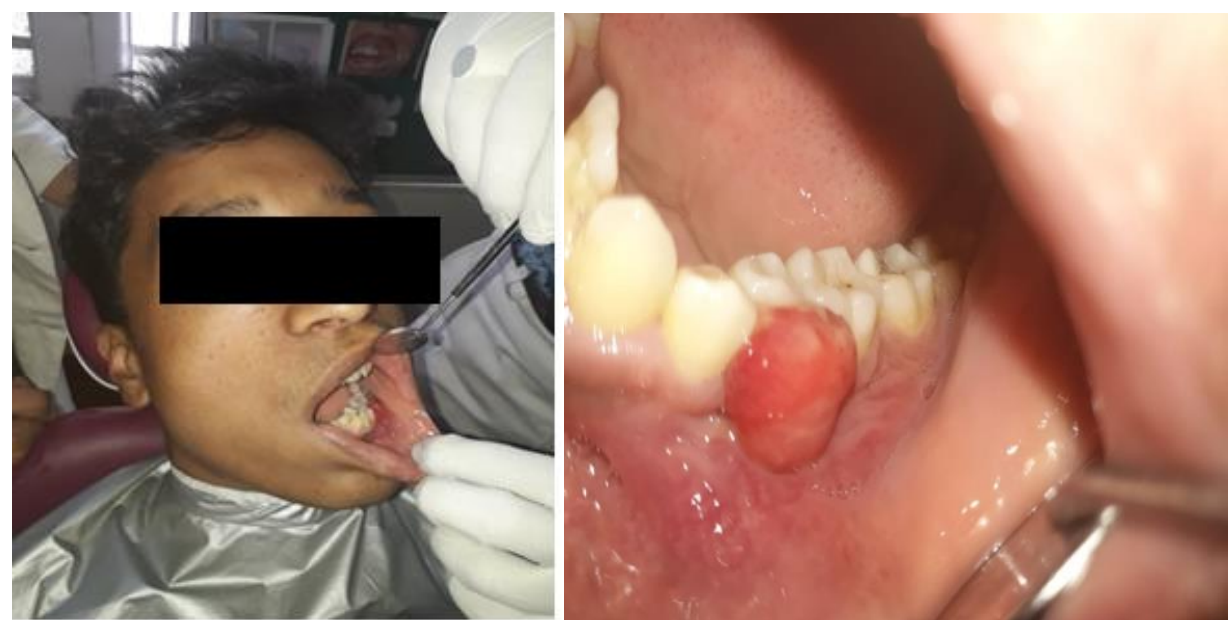

Fig. 1 and 2: Showing solitary, erythematous growth present in left mandibular premolar region
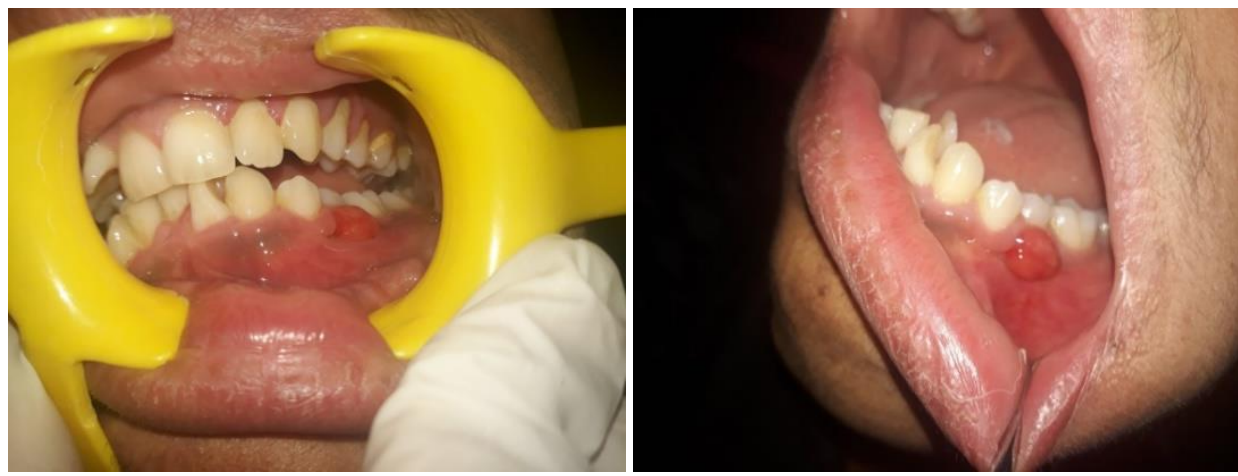

Fig. 3 and 4: Showing recurrence of lesion after 2 month of excision.
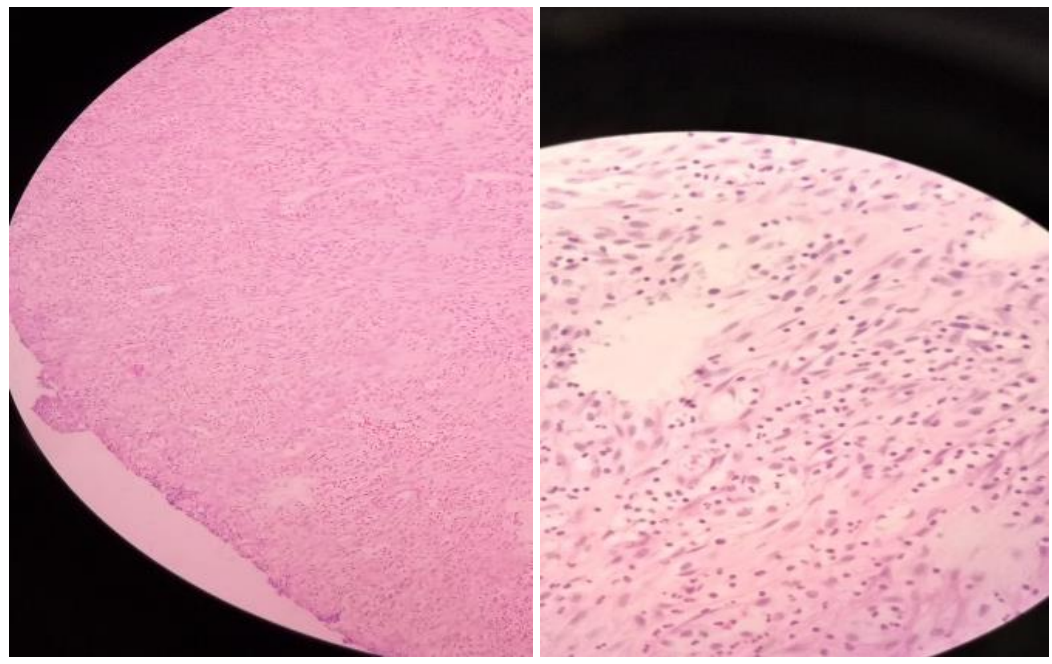

Fig. 5 and 6: Showing histopathologic picture at $10 \mathrm{X}$ and 6 showing histopathologic picture at $40 \mathrm{X}$

\section{Discussion}

Angioleiomyomas also referred to as angiomyoma, vascular Leiomyomas, or dermal angiomas, are benign smooth muscle tumors arising in the tunica media of vessels. ${ }^{7}$ In the oral cavity because of the paucity of the smooth muscle vascular Leiomyomas uncommon finding. Oral leiomyoma is seen more in men than in women, with a 1.43:1 ratio. $^{8}$ In a review, the distribution of 121 oral ALs was surveyed.$^{9}$ The most frequent site of development was

the lip (48.6\%), followed by the palate, buccal mucosa, tongue, mandible, buccal sulcus, labial sulcus, floor of the mouth, and gingiva. According to this report AL of the gingiva is very rare $(0.9 \%)$. ALs have a non-specific clinical appearance due to that it is difficult to distinguish them from similar lesions, such as Hemangioma, fibroma, angiofibroma, lipomas, and others. Histological examination is necessary for a definitive diagnosis. ${ }^{10}$ 
Malignant transformation of angioleiomyoma is very rare, there are several case studies describing angioleiomyosarcoma in the literature. ${ }^{11}$

Angioleiomyomas are characterized by slow growing masses, firm to the touch with color depending on depth and vascularity. It is usually asymptomatic, but some may cause pain and complicate swallowing. The average size is between 1 to $2 \mathrm{~cm}$ with a history of less than one year. ${ }^{12,13}$

When tumors are located in the gingiva or palate adjacent to the gingival sulcus they may be confused with periapical granuloma. However, it exhibit bone loss, or deep periodontal pockets typical of periodontal pathology. ALs usually don't cause bone resorption. Clinically, $55.9 \%$ of Angioleiomyomas are red in color, while the remainders are gray to white, or normal mucosal color. ${ }^{14}$

In the presented case lesion camouflaged as reactive periodontal pathology and it was difficult to clinically differentiate ALs from mesenchymal lesions because of its atypical location. It was diagnosed with the help of Histopathological examination. Hence in mesenchymal lesion which has similarities in clinical presentation HPE is gold standard.

\section{References}

1. Regezzi JA, Sciubba JJ, Jordan RCK. Oral pathology: clinical pathologic correlations. 4 ed. Missouri: Saunders; 2003.

2. Brad Neville, Douglas D. Damm, Carl Allen, Angela Chi. Oral and Maxillofacial Pathology. Saunders; 2015.

3. Stout AP. Solitary cutaneous and subcutaneous leiomyoma. Am J Cancer.1937;29:435.

4. Glas E. Beitrage zur pathologie der zungengrudtumoren. Wein Klin Wochenshr. 1905;18:747.

5. Veeresh M, Sudhakara M, Girish G, Naik C. Leiomyoma: a rare tumor in the head and neck and oral cavity: report of 3 cases with review. J Oral Maxillofac Pathol. 2013;17:281-287.
6. Silva Luiz Arthur Barbosa da, Medeiros Ana Miryam Costa de Oliveira Patrícia Teixeira de, Silveira Éricka Janine Dantas da, Miguel Márcia Cristina da Costa. Oral angioleiomyoma: report of a case and review of current findings. $J$.

Vasc Bras. [Internet]. 2017 Mar [cited 2017;16(1):68-72.

7. Ramesh P, Annapureddy SR, Khan F, Sutaria PD. Angioleiomyoma: a clinical, pathological and radiological review. Int J Clin Pract. 2004;58:587-591.

8. Brooks JK, Nikitakis NG, Goodman NJ, Levy BA. Clinicopathologic characterization of oral angioleiomyomas. Oral Surg Oral Med Oral Pathol Oral Radiol Endod. 2002;94:221-227.

9. Brooks JK, Nikitakis NG, Goodman NJ, Levy BA. Clinicopathologic characterization of oral angioleiomyomas. Oral Surg Oral Med Oral Pathol Oral Radiol Endodontol. 2002;94(2):221-227.

10. Ishikawa S, Fuyama S, Kobayashi T, Taira Y, Sugano A, Iino $\mathrm{M}$. Angioleiomyoma of the tongue: a case report and review of the literature. Odontol. 2016;104(1):119-22. PMid:25238675. http:// dx.doi.org/10.1007/s10266-014-0175-0.

11. Osman Fatih Arpağ, Ibrahim Damlar, Soydan Kılıç, Ahmet Altan, Zeynel Abidin Taş, Tümay Özgür. Angioleiomyoma of the gingiva: a report of two cases. J Korean Assoc Oral Maxillofac Surg. 2016;42:115-119

12. Liang H, Frederiksen NL, Binnie WH, Cheng YS. Intraosseous oral leiomyoma: systematic review and report of one case. Dentomaxillofac Radiol. 2003;32:285-290.

13. Wertheimer-Hatch L, Hatch GF 3rd, HatchB S KF, Davis GB, Blanchard DK, Foster RS Jr, et al. Tumors of the oral cavity and pharynx. World J Surg. 2000;24:395-400.

14. Koca H, Guneri P, Cetingol E, Onal T. A very rare of leiomyoma: mandibular angioleiomyoma. Int J Pediatr Otorhinolaryngol Extra. 2006;1:110-114.

How to cite this article: Sharma $\mathrm{P}$, Tariq S. Gingival angioleiomyoma mimicking as pyogenic granuloma- A report of rare case. J Oral Med, Oral Surg, Oral Pathol, Oral Radiol. 2018;4(4):204-206. 